\title{
Increasing incidence of HIV-associated tuberculosis in Romanian injecting drug users
}

\author{
Oprea Cristiana ${ }^{1,2}$, Ianache Irina ${ }^{2}$, Calistru Petre ${ }^{1,2}$, Nica Maria ${ }^{1,3}$, Ruta Simona ${ }^{1,4}$, Smith \\ Colette $^{5}$, Lipman Marc ${ }^{6,7}$
}

1 Carol Davila University of Medicine and Pharmacy, Bucharest, Romania

2 Victor Babes Clinical Hospital for Infectious and Tropical Diseases, Bucharest, Romania

3 Victor Babes Clinical Hospital for Infectious and Tropical Diseases, Laboratory of Bacteriology,

Bucharest, Romania

4 Stefan S. Nicolau Institute of Virology, Bucharest, Romania

5 Institute of Global Health, University College of London, United Kingdom

6 Royal Free London NHS Foundation Trust, London NW3, United Kingdom

7 UCL Respiratory, Division of Medicine, University College of London, United Kingdom

117 character summary:

In 2009-14, HIV/TB, TB drug resistance \& worse outcome significantly increased in Bucharest injecting drug users

\section{Background}

Although the incidence of tuberculosis (TB) is declining in most EU countries, and despite recent progress, notification rates in Romania are several times higher than the European mean of 13.5 per 100,000 . It is one of the 18 TB high-priority countries within the WHO European Region (1). In 2015, out of the 60,195 TB cases reported by the 30 EU/EEA countries, one-quarter were from Romania (2).

The number of injecting drug users (IDUs) in the general Romanian population has increased by almost 9\% since 2007 (3). Its geographic location ensures that Romania is part of the Balkan route of heroin trafficking. Moreover, in the last few years a new "legal drugs" market has arisen, with increasing use of psychoactive drugs, known as "ethnobotanicals". These are derived from cathinones and are a mixture of chemical powders such as mephedrone, MDPV (Methylenedioxypyrovalerone), 5-MeO-DALT, phenetylamine or benzopyrone. Ethnobotanicals have psychoactive effects similar to those produced by amphetamines. These drugs are 
commercialized as "spice - type" smoking drugs or synthetic psychoactive substances that can be injected or sniffed (3). They are cheap and therefore affordable for most IDUs. They are also highly addictive and require multiple injections (6-10 times/day) - thus the risk of acquiring bacterial and viral infections with their use is very high (3-7).

By the end of 2014, there were 12,886 people living with HIV/AIDS (PLWH) in Romania. The number of newly diagnosed cases per year has increased progressively, from 445 in 2007 to over 900 in 2014 (8). While the majority of HIV/AIDS cases reported during the 1990s arose from the cohort of children infected via the parenteral mode in the late 1980s, the HIV epidemic in Romania today now follows the general European trend, with an increasing incidence in IDUs and men who have sex with men (MSM). In 2007, IDUs accounted for $2 \%$ of new cases of HIV, by 2014 this had increased to more than $20 \%$, associated with a concomitant spread of hepatitis B and C and severe cases of systemic bacterial infections (8-11). In addition, in 2014 16\% of Romanian IDUs diagnosed with HIV also had pulmonary TB (9).

The "Victor Babes" Clinical Hospital for Infectious Diseases (SVB), Bucharest, is a tertiary referral centre which manages a large national case-load of known HIV-infected IDUs. The aims of our study were: to determine the prevalence of TB among IDUs newly diagnosed with HIV admitted to SVB; to describe their demographic and clinical characteristics according to TB co-infection status; and to consider the impact of TB co-infection, TB drug resistance and site of disease on mortality.

\section{Methods}

\section{Patient population}

We performed a prospective study of adult IDUs with HIV admitted to SVB between January 2009 and December 2014. It is standard practice in Romania for people who inject drugs to be admitted at the time of HIV diagnosis. HIV testing is mandatory for all new TB diagnoses, and all patients with suspected or diagnosed TB are also admitted. Therefore, almost all IDUs diagnosed with TB who are HIV positive are managed in our service, plus $>90 \%$ of those with HIV mono-infection. Social, demographic and clinical characteristics were obtained from clinical databases from the time of admission until the date of last follow-up of on 31 December 2015.

All patients satisfying study criteria gave informed consent to participate in this work. 


\section{Tuberculosis diagnosis and disease classification}

TB diagnosis was classified as definitive (positive mycobacterial cultures, molecular tests, MTBPCR and histopathological examination) or presumptive (based on clinical, radiological findings, histopathology and response to empirical treatment). Clinical forms of TB were categorized as pulmonary TB, extra-pulmonary TB and disseminated TB (in patients with both pulmonary and extra-pulmonary involvement).

In line with recommended definitions, a CD4 cell count $<350 / \mathrm{mm}^{3}$ at the time of HIV diagnosis was considered as late presentation (LP) and a CD4 $<200 / \mathrm{mm}^{3}$, advanced HIV disease (AHD) $(12,13)$.

\section{Statistical analysis}

Individuals were followed from the date of HIV diagnosis until the time of death or last followup at $31^{\text {st }}$ December 2015. The prevalence of TB co-infection at HIV diagnosis or immediately after this was summarized by calendar year, and investigated using a test for trend. Demographic and clinical characteristics at the time of HIV diagnosis were compared according to TB co-infection status. Comparisons of categorical variables were made using chi-squared test or Fisher's exact test, as appropriate. Comparisons of continuous variables, such as CD4 count, age and HIV load were made using the Wilcoxon rank sum test. Amongst the subgroup with TB, we calculated the short-term mortality as the percentage that died within 3 months of diagnosis and the longer-term mortality as the death rate per 1000 person-years from three months post-diagnosis onwards, according to the site of TB. Finally, the time to death was compared between HIV and TB-co infected IDUs and HIV-infected IDUs without TB using standard survival methods of Kaplan-Meier plots, and log rank tests.

Analyses were performed using SPSS version 20 and STATA version SE 14.0. A p value of $<0.05$ was considered to demonstrate a statistically significant difference.

\section{Results}

Comparison of HIV-infected IDUs with and without TB

A total of 598 injecting drug users were diagnosed with HIV, with a median follow-up of 30.0 (IQR 17.8, 42.1) months. 170 (28.5\%) were also diagnosed with active TB, of whom 153/170 (90\%) had a simultaneous diagnosis of both HIV and TB. The remaining 17/170 (10\%) were diagnosed with TB a median of 140 (IQR 100 -284) days after HIV diagnosis. TB prevalence among HIV infected IDUs rose dramatically from 2009 to 2013 with a slight decrease in 2014 $(p<0.001)$ (Figure 1) 
The majority of IDUs were young, from urban areas and male (Table 1). There were no differences according to TB co-infection status with respect to gender, age at HIV diagnosis and median duration of injecting drug use. A significantly higher proportion of the HIV/TB coinfected IDUs were unemployed and of low educational level compared to HIV-infected IDUs without TB. A history of multiple sexual partners/unprotected sexual intercourse was significantly more common in IDUs without TB.

About one third of the patients, irrespective of TB status, had used drugs for more than 10 years. Few reported starting drug use within the last 12 months (2.3\% [4/170] vs. 3.9\% [17/428]; $p=0.33$ ). The majority of IDUs injected both heroin and psychoactive drugs. However, TB co-infected patients were more likely to exclusively use ethnobotanicals, or in combination with other smoked drugs; whereas heroin use alone or in combination with other psycho-active drugs was more commonly reported in those without TB (Table 1).

\section{HIV infection status and viral hepatitis co-infection}

Blood CD4 cell count at HIV diagnosis was available for $84.6 \%$ (506) IDUs: $100 \%$ (170/170) with and $78.5 \%$ (336/428) without TB. HIV load was available in $36.8 \%$ (220) IDUs: $33.5 \%$ (57) with TB and $38.1 \%$ (163) without TB. The median CD4 cell count $/ \mathrm{mm}^{3}$ at HIV diagnosis was lower for IDUs with TB compared to non-TB IDUs: $75 / \mathrm{mm}^{3}$ vs. $450 / \mathrm{mm}^{3}(\mathrm{p}<0.0001)$ (Table 2). In addition, a significantly higher percentage of IDUs who developed TB were diagnosed as late-presenters (CD4 cell count $<350 / \mathrm{mm}^{3}$ ) compared to the non TB IDUs $(p<0.0001)$. Even so, 26 patients (15.2\%) developed TB with a blood CD4 $>500$ cell $/ \mathrm{mm}^{3}$. Among those who injected drugs for more than 10 years, HIV/TB co-infected IDUs had more severe immunosuppression (median CD4 cell counts $51 / \mathrm{mm}^{3}$ vs $478 / \mathrm{mm}^{3}$ in those without TB, $\mathrm{p}<0.0001$ ). The median HIV load at HIV diagnosis was higher for TB co-infected patients (5.6 $\log _{10}$ vs. $4.9 \log _{10}, p=0.0002$ ). Almost all IDUs $(90.0 \%, 198 / 220)$ had a HIV viral load $>10^{5}$ copies $/ \mathrm{ml}$ (Table 2 ).

Irrespective of their TB status, most patients were co-infected with HCV (98.3\% [588]). IDUs without TB were more likely to be $\mathrm{HBs} \mathrm{Ag}$ positive (Table 2, $\mathrm{p}=0.004$ ). Overall, antiretroviral treatment (ART) was ever initiated in $30.1 \%$ (180) patients, with a higher percentage starting in the TB co-infected subgroup $(p<0.0001)$.

\section{Clinical characteristics of HIV-infected IDUs with TB}

105 patients had positive mycobacterial cultures, and 15 positive MTB-PCR samples. A total of 96/170 (56.4\%) patients had only positive cultures: 90 from sputum, 3 from cerebro-spinal fluid (CSF), 2 from lymph node aspirate and 1 from bronchial aspirate. TB diagnosis was established only by MTB-PCR in 6/170 (3.5\%) cases, from sputum and bronchial aspirate in 4 cases and CSF 
in 2. There were also $9 / 170$ (5.2\%) patients who had both positive cultures and MTB-PCR (lymph nodes 4, CSF 3, ascites 1 and pleural fluid 1 ). In the remaining 65/170 cases (38.2\%) the diagnosis was presumptive.

The majority of IDUs diagnosed with TB developed pulmonary disease, 103/170 (60.6\%), approximately a quarter had disseminated disease (49/170; $28.8 \%$ ) and $10.5 \%$ (18) had extrapulmonary disease. Among patients with extra-pulmonary TB, 10 were diagnosed with TB meningoencephalitis, 6 with intestinal TB, 1 with osteo-articular TB and 1 hepato-splenic TB.

All 105 TB positive cultures underwent drug susceptibility testing. Overall, 28 (26.7\%) had clinically relevant drug resistance. Resistance to either INH or RMP was present in 10 (9.5\%), 7 (6.6\%) were resistant to both INH and RMP (ie MDR) and 11 (10.4\%) isolates were extensively drug resistant (XDR) - of which 10 were identified in 2014.

Time to death according to presence of TB

A total of 72 individuals died (12\%; 72/598), comprising 23.5\% (40/170) of those with TB compared to $7.4 \%(32 / 428)$ of those without, $p<0.0001$ (Figure $2 A)$. The percentage of people still alive at one year was 93.5\% (95\% Cl 90.7\%, 95.4\%; Kaplan-Meier estimate) for those with HIV only, and $80.6 \%(73.8 \%, 85.8 \%)$ in IDUs co-infected with both TB and HIV.

Time to death according to site of TB disease and presence of TB drug resistance

When considering the sub-group co-infected with both HIV and TB, the incidence of early (within 3 months of diagnosis) and late (from 3 months onwards) mortality was higher in IDUs with extra-pulmonary TB, and those with XDR strains (Table 3). These results were corroborated in Kaplan-Meier plots demonstrating different survival times according to the site of TB disease $(p=0.0026$; Figure 2B) and the presence of a drug-resistant strain ( $p=0.024$; Figure $2 C)$.

\section{Discussion}

In 2015, there were 15,195 cases of TB in Romania, giving a notification rate of 76.5 per 100.000 inhabitants (2). TB is one of the commonest opportunistic infections associated with HIV infection (8). Among TB cases nationally the HIV incidence per 100 people has risen from 0.11 in 1990 to 0.93 in 2014, with a peak of 1.37 in 2011 (8). In our prospective study we report an approximately two-fold increase in the prevalence of HIV/TB co-infection in IDUs presenting 
at a Romanian tertiary care centre between 2009 and 2014. The majority of patients were diagnosed with both HIV and TB simultaneously, and had advanced HIV infection.

It has been previously shown that PLWH with lower CD4 counts are more likely to develop TB when compared to people with better immune status at HIV diagnosis (14-17). Similar to data reported annually from ECDC (2), we found pulmonary TB to be the most frequent clinical form of disease. However, extra pulmonary TB was associated with more severe immunosuppression and a higher mortality - likely as a result of over half of the cases presenting with TB meningitis.

The mortality rate in our study was higher for IDUs diagnosed with TB. This is in line with other European reports which also found a greater risk of death in patients with TB - in particular during the first year following HIV diagnosis (18). Amongst IDUs with TB, the mortality rate was greatest in those with extra pulmonary disease, and people with XDR TB.

Although ART increases survival in HIV/TB co-infected patients (19), delay in its initiation, itself often due to late diagnosis, is associated with worse outcome (18). In our centre, antiretroviral treatment was started more often in IDUs with TB - usually due to their presentation with severe immunosuppression. The limited information regarding adherence to ART in our patient population makes it difficult to comment on its impact - though it is perhaps relevant that survival was significantly worse in patients with TB co-infection over the first two years from HIV diagnosis (Figure 2A).

We found the profile of a HIV/TB co-infected IDU to be an unemployed urban male, with a low level of education, who was using mainly ethnobotanical drugs. Smoked drugs were more often used in combination with injectables by TB patients. This is in agreement with literature highlighting the association between inhaled crack cocaine and smear-positive TB possibly due to respiratory damage (20).

Although the percentage of TB in IDUs was higher in patients with a history of imprisonment, this was not statistically significant. Other risk factors such as tattoos or piercings commonly reported to be associated with TB $(14,15,21,22)$, were not identified in our study.

The frequent use of injectable drugs, in particular ethnobotanicals which involve multiple administrations per day, often using unsterile injecting equipment, has been associated with a very high frequency of viral hepatitis $(3-7,11)$. Inevitably, almost all IDUs from our study were HCV antibody positive; though Hepatitis B surface antigen positivity was more common in IDUs without TB. This may relate to a greater proportion of these patients reporting multiple partners or unprotected sexual intercourse. The data suggesting that TB IDUs reported less 
sexual partners than non-TB IDUs might be explained by the former group being less social, and hence possibly less likely or able to seek healthcare and/or be advised to do so by others when unwell. This would be consistent with the worse immunological status and higher HIV load found in the TB IDUs at the time of their HIV diagnosis.

Studies performed in Eastern Europe have highlighted the possible association between injecting drug use, HIV and MDR-TB (23). Over the last decade, drug-resistant TB has become a particular challenge for TB management. This has had a major impact on survival in IDUs (24). The number of MDR and XDR TB cases in our study increased annually, spiking in the last year of this report. It is a particular concern as patients with drug resistance are harder to treat, and likely therefore to be infectious to others for longer. The dissemination of resistant TB strains among vulnerable groups, as well as the general population, represents a challenge for health care systems that are already struggling to manage patients with complex psycho-social issues. The higher costs of treatment of such patients do not necessarily translate into better outcomes. Despite the greater availability of ART in Eastern Europe countries over the last decade, mortality among HIV infected patients with drug-resistant TB has been reported to approach $30 \%(25,26)$.

\section{Limitations}

Despite our hospital being a large, national centre providing care to HIV-infected IDUs from all over Romania, this is a single site study performed over a relatively short period of time. However, we are unaware of similar data on HIV and TB in Romanian IDUs.

The diagnosis of TB was definitive (confirmed by positive culture) in over half of our patients. This is in line with that reported by ECDC in 2013 for all TB cases in both Europe (almost 60\%) and Romania (65.2\%) (2). A limitation of our study is that blood CD4 cell counts and HIV load were not available for all study subjects at HIV diagnosis. Also, the recording of antiretroviral use was incomplete - making it difficult to compare our data with that from other countries; though we are aware that this is a common challenge in Eastern Europe $(25,26)$. Finally, we had no post-mortem histopathological diagnoses to confirm the cause of death in our IDU population.

\section{Conclusions}

TB prevalence in HIV infected Romanian IDUs has increased over the last decade and significant TB drug resistance has emerged as a particular issue. The management of IDUs with HIV is difficult due to their severe addiction and/or neuro-psychiatric disorders plus possible poor adherence to ART. Under these circumstances we believe that strengthening HIV transmission prevention methods, particularly in identified risk groups, whilst addressing the surge in TB is 
vital. A multidisciplinary approach, including national policies for routine HIV and hepatitis testing for IDUs, improvement of harm-reduction programs (needle/syringe exchange programs and opioid substitution treatment services), linkage to care and treatment for HIV, viral hepatitis and TB are needed to be implemented urgently if we are to improve outcomes in this vulnerable patient population.

\section{Acknowledgments}

Roxana Radoi MD, lonut Popa MD, Simona Erscoiu MD, Ph.D., Luminita Ene MD, Ph.D. Gratiela Tardei MD, Ph.D.

Victor Babes Hospital for Infectious and Tropical Diseases, Bucharest, Romania

\section{References}

1. WHO. Plan to stop TB in 18 High-priority Countries in the European Region, 2007-2015 2007 [updated 2007; cited July 2017]. Available from: http://www.euro.who.int/_data/assets/pdf_file/0005/68180/E91049.pdf.

2. ECDC, WHO. Tuberculosis surveillance and monitoring in Europe 2017 Stockholm:: European Centre for Disease Prevention and Control; 2017 [updated 2017; cited 2017]. Available from:

https://ecdc.europa.eu/sites/portal/files/media/en/publications/Publications/ecdctuberculosis-surveillance-monitoring-Europe-2017.pdf.

3. EMCDDA. Romania New Developments, Trends and In-depth Information on Selected Issues ; European Monitoring Centre for National (EMCDDA); Anti-drug Agency Drugs and Drug Addiction 2011 [updated 2012; cited July 2012]. Available from:

http://www.ana.gov.ro/rapoarte\%20nationale/en/National\%20Report\%20on\%20Drugs\%20201 1.pdf.

4. ACMD. Consideration of the cathinones Advisory Council on the Misuse of Drugs, Home Office, London 2010 [updated 2010; cited 2017 July]. Available from:

http://www.homeoffice.gov.uk/publications/drugs/acmd1/acmd-cathinodes-report-2010.

5. Maftei L. The main characteristics of the Romanian illegal drug markets. Eastern Journal of European Studies. 2012;3(1):189-204.

6. EMCDDA, Anti-Drog AN. National Report to the European Monitoring Centre for National (EMCDDA), Romania 2014 [Raport National privind Situatia Drogurilor 2014 Romania; Noi evoluţii şi tendinţe] 2014 [cited 2014]. Available from: http://www.ana.gov.ro/rapoarte\%20nationale/RO_RN_2014.pdf.

7. Botescu A. Risk assessment of new psychoactive substances consumption among children and youth in Romania. Network RHR; 20122012.

8. CNLAS. The evolution of HIV/AIDS in Romania 31 December 2014; 2014 [updated July 2014]. Available from: http://www.cnlas.ro/images/doc/31122014_rom.pdf.

9. CNLAS. Specific Challenges of the HIV Epidemic in Romania 2013; 2013 [updated 2013; cited 2017 July ]. Available from: http://www.cnlas.ro/images/doc/spec_chall_HIV.pdf. 
10. EMCDDA. Raportul national privind situatia drogurilor 2013; Romania; Noi evolutii, tendinte si informatii detaliate cu privier la temele de interes European 2013 [updated 2013; cited 2013 Decembre]. Available from:

http://www.ana.gov.ro/rapoarte\%20nationale/RN_2013.pdf.

11. Oprea C, Ceausu E, Ruta S. Ongoing outbreak of multiple blood-borne infections in injecting drug users in Romania. Public health. 2013;127(11):1048-50.

12. Johnson M, Sabin C, Girardi E. Definition and epidemiology of late presentation in Europe. Antiviral therapy. 2010;15 Suppl 1:3-8.

13. Antinori A, Coenen T, Costagiola D, et al. Late presentation of HIV infection: a consensus definition. HIV medicine. 2011;12(1):61-4.

14. Sterling TR, Pham PA, Chaisson RE. HIV infection-related tuberculosis: clinical manifestations and treatment. Clinical infectious diseases : an official publication of the Infectious Diseases Society of America. 2010;50 Suppl 3:S223-30.

15. Girardi E, Palmieri F, Angeletti C, et al. Impact of Previous ART and of ART Initiation on Outcome of HIV-Associated Tuberculosis. Clinical and Developmental Immunology. 2012;2012:8.

16. Batista J, de Albuquerque Mde F, Maruza M, et al. Incidence and risk factors for tuberculosis in people living with HIV: cohort from HIV referral health centers in Recife, Brazil. PloS one. 2013;8(5):e63916.

17. Karo B, Haas W, Kollan C, et al. Tuberculosis among people living with HIV/AIDS in the German ClinSurv HIV Cohort: long-term incidence and risk factors. BMC infectious diseases. 2014;14:148.

18. Zenner D, Abubakar I, Conti S, et al. Impact of TB on the survival of people living with HIV infection in England, Wales and Northern Ireland. Thorax. 2015;70(6):566-73.

19. Manosuthi W, Wiboonchutikul S, Sungkanuparph S. Integrated therapy for HIV and tuberculosis. AIDS research and therapy. 2016;13:22.

20. Story A, Bothamley G, Hayward A. Crack cocaine and infectious tuberculosis. Emerging infectious diseases. 2008;14(9):1466-9.

21. Ruutel K, Karnite A, Talu A, et al. Prevalence of IGRA-positivity and risk factors for tuberculosis among injecting drug users in Estonia and Latvia. The International journal on drug policy. 2014;25(1):175-8.

22. Paraskevis D, Nikolopoulos G, Fotiou A, et al. Economic recession and emergence of an HIV-1 outbreak among drug injectors in Athens metropolitan area: a longitudinal study. PloS one. 2013;8(11):e78941.

23. van den Hof S, Tursynbayeva A, Abildaev $T$, et al. Converging risk factors but no association between HIV infection and multidrug-resistant tuberculosis in Kazakhstan. The international journal of tuberculosis and lung disease : the official journal of the International Union against Tuberculosis and Lung Disease. 2013;17(4):526-31.

24. WHO. Integrating collaborative TB and HIV services within a comprehensive package of care for people who inject drugs - WHO Consolidated guidelines Geneva2016 [updated 2016; cited 2017 July]. Available from:

http://apps.who.int/iris/bitstream/10665/204484/1/9789241510226_eng.pdf?ua=1.

25. Podlekareva DN, Mocroft A, Post FA, et al. Mortality from HIV and TB coinfections is higher in Eastern Europe than in Western Europe and Argentina. AIDS. 2009;23(18):2485-95. 
26. Podlekareva DN, Efsen AM, Schultze A, et al. Tuberculosis-related mortality in people living with HIV in Europe and Latin America: an international cohort study. The lancet HIV. 2016;3(3):e120-31.

Figure 1. Number and percentage of HIV-infected injecting drug users diagnosed with TB January 2009 to December 2014.

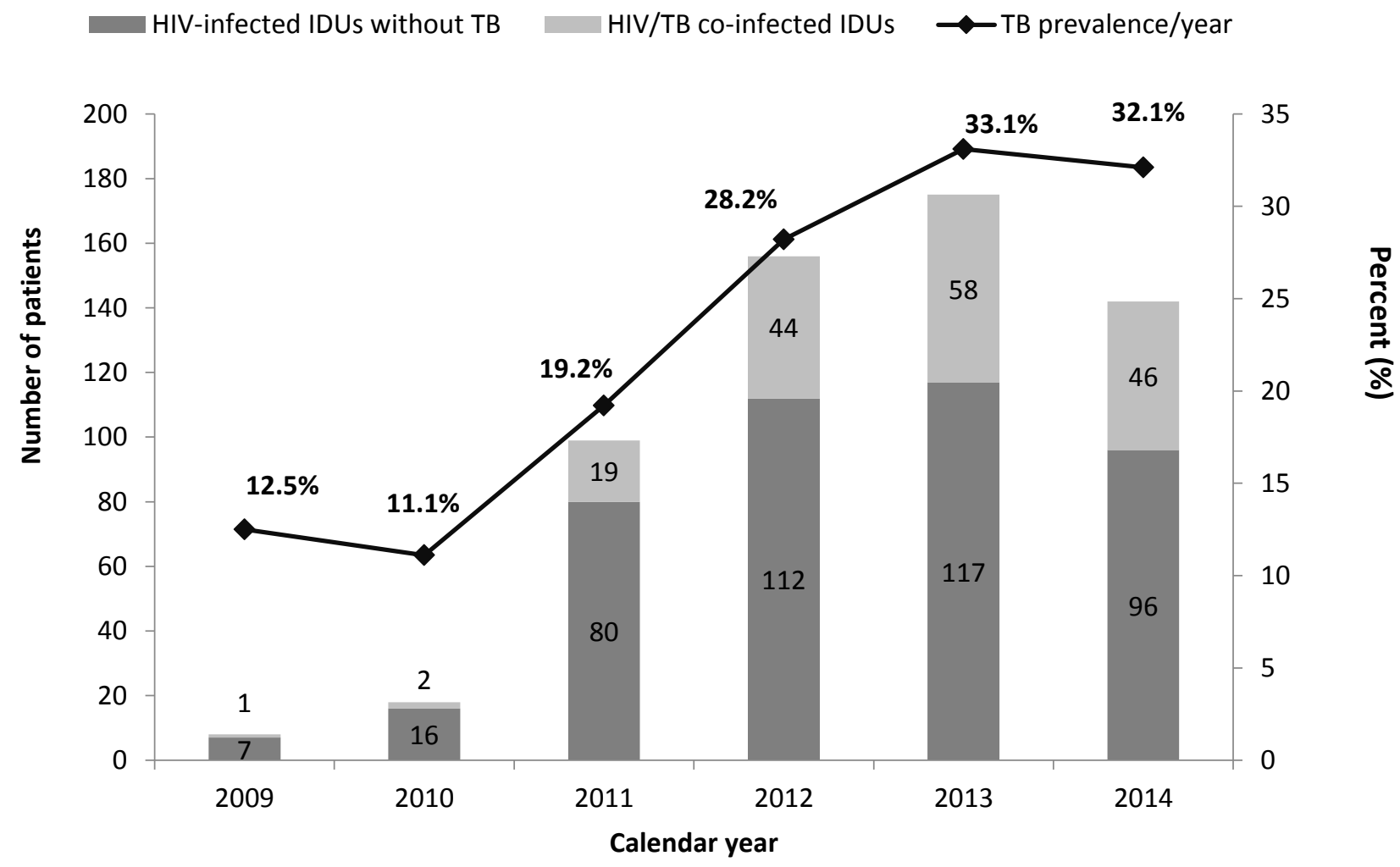


Table 1. Socio-demographic characteristics, lifestyle factors and injecting drug behavior in HIV infected injecting drug users with and without tuberculosis at the time of HIV diagnosis

\begin{tabular}{|c|c|c|c|c|}
\hline & $\begin{array}{l}\text { Total } \\
\mathrm{n}=598\end{array}$ & $\begin{array}{l}\text { IDUs with TB } \\
n=170\end{array}$ & $\begin{array}{l}\text { IDUs without TB } \\
n=428\end{array}$ & $p$ value \\
\hline \multicolumn{5}{|l|}{ Socio-demographic variables } \\
\hline Male & $504(84.2)$ & $144(84.7)$ & $360(84.1)$ & 0.90 \\
\hline Urban areas & $543(90.8)$ & $153(90.0)$ & $390(91.1)$ & 0.64 \\
\hline Median age & $29(25-33)$ & $30(25-34)$ & $29(25-33)$ & 0.07 \\
\hline Unemployed $\quad \mathrm{n}(\%)$ & $373(62.4)$ & $138(81.1)$ & $235(54.9)$ & $<0.0001$ \\
\hline Fewer than 8 years' education $n(\%)$ & $442(73.9)$ & $150(88.2)$ & $292(68.2)$ & $<0.0001$ \\
\hline $\begin{array}{r}\text { Median age at drug use initiation } \\
\text { (years, IQR) }\end{array}$ & $19(16-24)$ & $20(16-26)$ & $19(16-23)$ & 0.02 \\
\hline $\begin{array}{l}\text { Median time on drugs } \\
\qquad \text { (months, IQR) }\end{array}$ & $108(48-156)$ & $102(48-144)$ & $108(48-156)$ & 0.23 \\
\hline Type of drug $\quad n(\%)$ & & & & \\
\hline Heroin alone & $107(17.8)$ & $20(11.7)$ & $87(20.3)$ & $<0.0001$ \\
\hline Ethnobotanicals alone & $88(14.7)$ & $40(23.5)$ & $48(11.2)$ & \\
\hline Heroin \& ethnobotanicals & $331(55.3)$ & $95(55.8)$ & $236(55.1)$ & \\
\hline $\begin{array}{l}\text { Heroin, ethnobotanicals and other } \\
\text { injecting psycho-active drugs }\end{array}$ & $47(7.8)$ & $3(1.8)$ & $44(10.2)$ & \\
\hline $\begin{array}{l}\text { Heroin, ethnobotanicals and non- } \\
\text { injecting drugs }\end{array}$ & $25(4.1)$ & $12(7.1)$ & $13(3.0)$ & \\
\hline \multicolumn{5}{|l|}{ Risk factors } \\
\hline Smoking & $355(59.3)$ & $104(61.1)$ & $251(58.6)$ & 0.58 \\
\hline Alcohol consumption & $85(14.2)$ & $26(15.2)$ & $59(13.7)$ & 0.69 \\
\hline Imprisonment & $139(23.2)$ & $48(28.2)$ & $91(21.2)$ & 0.06 \\
\hline Tattoos & $450(75.2)$ & $123(72.3)$ & $327(76.4)$ & 0.35 \\
\hline $\begin{array}{ll}\text { Piercing } & \mathrm{n}(\%) \\
\end{array}$ & $38(6.3)$ & $5(2.9)$ & $33(7.7)$ & 0.03 \\
\hline $\begin{array}{l}\text { Surgery/blood transfusion history } \\
\qquad \mathrm{n}(\%)\end{array}$ & $137(22.9)$ & $43(25.2)$ & $94(21.9)$ & 0.38 \\
\hline $\begin{array}{l}\text { Multiple sexual partners *and } \\
\text { unprotected sexual intercourse } \\
\qquad \mathrm{n}(\%)\end{array}$ & $241(40.3)$ & $38(22.3)$ & $203(47.4)$ & $<0.0001$ \\
\hline Needle sharing & $59(9.8)$ & $12(7.0)$ & $47(10.9)$ & 0.17 \\
\hline
\end{tabular}

IDU=injecting drug user; IQR=inter-quartile range; TB=tuberculosis.

P-values calculated using chi-squared test or Fisher's Exact test for categorical variables and Wilcoxon rank sum test for continuous variables. 
Table 2. Immunological and virological status at HIV diagnosis of injecting drug users with and without tuberculosis

\begin{tabular}{|c|c|c|c|c|}
\hline & $\begin{array}{c}\text { Total } \\
n=598\end{array}$ & $\begin{array}{c}\text { IDUs with TB } \\
n=170\end{array}$ & $\begin{array}{c}\text { IDUs without TB } \\
n=428\end{array}$ & $p$ value \\
\hline $\begin{array}{r}\text { CD4 cell count (cells } / \mathrm{mm}^{3} \text { ) } \\
\mathrm{N} \text { with measurement (\%) } \\
\text { Median (IQR) }\end{array}$ & $\begin{array}{c}506(84.6) \\
371(110-630)\end{array}$ & $\begin{array}{l}170(100.0) \\
75(20-330)\end{array}$ & $\begin{array}{c}336(78.5) \\
450(264-695)\end{array}$ & $<0.0001$ \\
\hline $\begin{array}{l}\text { Late-presenter** } \\
\left(\text { CD4 cell count }<350 / \mathrm{mm}^{3}\right) \quad \mathrm{n}(\%)\end{array}$ & $247(48.8)$ & 129 (75.9) & $118(35.1)$ & $<0.0001$ \\
\hline $\begin{array}{l}\text { Advanced HIV disease** } \\
\left(\text { CD4 cell count }<200 / \mathrm{mm}^{3}\right)\end{array}$ & $176(34.8)$ & $112(65.8)$ & $64(19.0)$ & $<0.0001$ \\
\hline $\begin{array}{l}\begin{array}{l}\text { Median HIV viral load } \quad\left(\log _{10}\right. \\
\text { copies/mL) }\end{array} \\
\\
\end{array}$ & $\begin{array}{c}220(36.8) \\
5.1(4.6-5.8)\end{array}$ & $\begin{array}{c}57(33.5) \\
5.6(5.2-6.2)\end{array}$ & $\begin{array}{c}163(38.1) \\
4.9(4.5-5.5)\end{array}$ & 0.0002 \\
\hline $\begin{array}{l}\text { Number of IDUs who initiated ART * } \\
\qquad \mathrm{n}(\%)\end{array}$ & $\begin{array}{c}180 \\
(30.1)\end{array}$ & $\begin{array}{c}81 \\
(47.6)\end{array}$ & $\begin{array}{c}99 \\
(23.1)\end{array}$ & $<0.0001$ \\
\hline Anti HCV antibody positive & $\begin{array}{c}588 \\
(98.3)\end{array}$ & $\begin{array}{c}168 \\
(98.8)\end{array}$ & $\begin{array}{c}420 \\
(98.1)\end{array}$ & 0.73 \\
\hline HBs Antigen positive & $\begin{array}{c}76 \\
(12.7)\end{array}$ & $\begin{array}{c}11 \\
(6.4)\end{array}$ & $\begin{array}{c}65 \\
(15.1)\end{array}$ & 0.004 \\
\hline
\end{tabular}

${ }^{*}$ At any point over follow-up

** Of those with an available CD4 measurement

$A R T=$ Antiretroviral therapy; HBs=Hepatitis B surface; $H C V=$ hepatitis $C$ virus; IDU=injecting drug user; IQR=inter-quartile range; $T B=$ tuberculosis.

P-values calculated using chi-squared test or Fisher's Exact test for categorical variables and Wilcoxon rank sum test for continuous variables. 
Table 3. Blood CD4 cell count at diagnosis and mortality among HIV/TB co-infected patients, stratified by clinical features of TB and resistance profile of identified Mycobacterium tuberculosis strains

\begin{tabular}{|c|c|c|c|c|c|c|c|c|}
\hline & \multirow{2}{*}{$\begin{array}{c}\text { Number } \\
\mathbf{N}(\%)\end{array}$} & \multirow{2}{*}{$\begin{array}{c}\text { CD4 } \\
\text { count at } \\
\text { diagnosis } \\
\text { (cells/mm³) } \\
\begin{array}{c}\text { Median } \\
\text { (IQR) }\end{array}\end{array}$} & \multirow{2}{*}{\begin{tabular}{|c|} 
Ever died \\
$\mathbf{N}(\%)$
\end{tabular}} & \multicolumn{2}{|c|}{ Early death* } & \multicolumn{3}{|c|}{ Late death** } \\
\hline & & & & $\mathbf{N}(\%)$ & $95 \% \mathrm{Cl}$ & $\begin{array}{l}\mathrm{N} / \\
\text { person- } \\
\text { years }\end{array}$ & $\begin{array}{l}\text { Rate } \\
* * *\end{array}$ & $95 \% \mathrm{Cl}$ \\
\hline \multicolumn{9}{|c|}{ Site of disease ( $n=170$ IDUs diagnosed with TB) } \\
\hline Pulmonary TB & $\begin{array}{c}103 \\
(60.6)\end{array}$ & $\begin{array}{c}175 \\
(30,459)\end{array}$ & $18(17.5)$ & $8(7.8)$ & $3.4,14.7$ & $10 / 2766.2$ & 3.6 & $1.7,6.7$ \\
\hline $\begin{array}{l}\text { Extra pulmonary } \\
\text { TB }\end{array}$ & $18(10.5)$ & $\begin{array}{c}25 \\
(12,64)\end{array}$ & $9(50.0)$ & $7(38.9)$ & $17.2,64.3$ & $2 / 338.5$ & 5.9 & $0.7,21.3$ \\
\hline Disseminated TB & $49(28.8)$ & $\begin{array}{c}30 \\
(13,124)\end{array}$ & $13(26.5)$ & $8(16.3)$ & $7.3,29.7$ & $5 / 966.9$ & 5.2 & $1.7,12.1$ \\
\hline \multicolumn{9}{|c|}{ Resistance profile ( $n=105$ positive cultures) } \\
\hline Fully susceptible & $77(73.3)$ & $\begin{array}{c}50 \\
(15,248)\end{array}$ & $16(20.8)$ & $8(10.4)$ & $4.6,19.4$ & $8 / 1709.2$ & 4.7 & $2.0,9.2$ \\
\hline $\begin{array}{l}\text { Resistant to INH or } \\
\text { RMP }\end{array}$ & $10(9.5)$ & $\begin{array}{c}28 \\
(19,58)\end{array}$ & $4(40.0)$ & $3(30.0)$ & $6.7,65.2$ & $1 / 204.5$ & 4.9 & $0.1,27.3$ \\
\hline MDR & $7(6.6)$ & $\begin{array}{c}105 \\
(21,392)\end{array}$ & $1(14.2)$ & $0(0.0)$ & $0.0,41.0$ & $1 / 193.2$ & 5.2 & $0.1,28.8$ \\
\hline XDR & $11(10.4)$ & $\begin{array}{c}42 \\
(12,84)\end{array}$ & $8(72.2)$ & $4(36.3)$ & $10.9,69.2$ & $4 / 100.0$ & 40.0 & $10.9,102.4$ \\
\hline \multicolumn{9}{|c|}{$\begin{array}{l}\text { * Within } 3 \text { months of TB diagnosis } \\
\text { ** From } 3 \text { months after TB diagnosis onwards } \\
\text { *** Per } 1000 \text { person-years }\end{array}$} \\
\hline
\end{tabular}

$\mathrm{Cl}=$ Confidence interval; IDU=injecting drug user; INH=Isoniazid; IQR=inter-quartile range; MDR=MultiDrug Resistance; RMP=Rifampicin; $T B=$ tuberculosis; $X D R=$ Extensive Drug Resistance. 
Figure 2. Kaplan-Meier plots survival estimates depending on TB co-infection (2A), clinical form of TB (2B) and resistance profile (2C)

A)

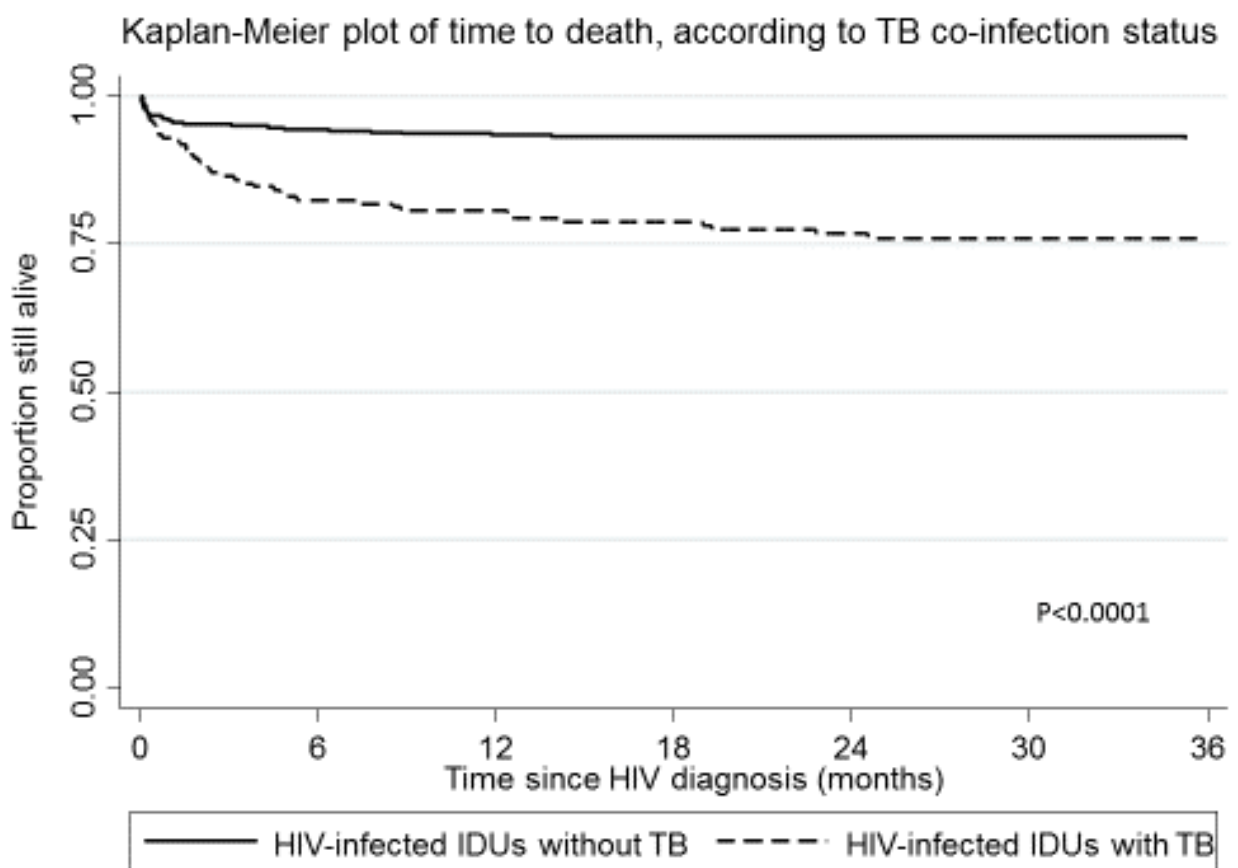

B)

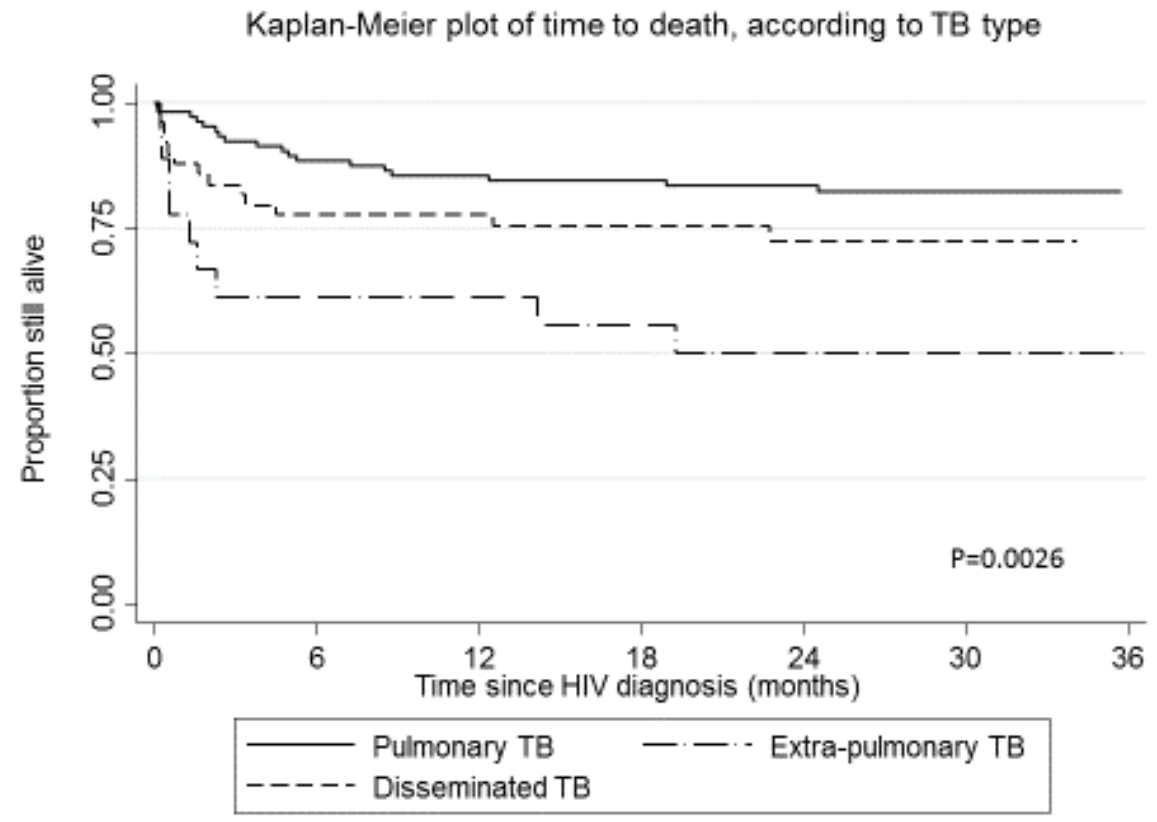


C)

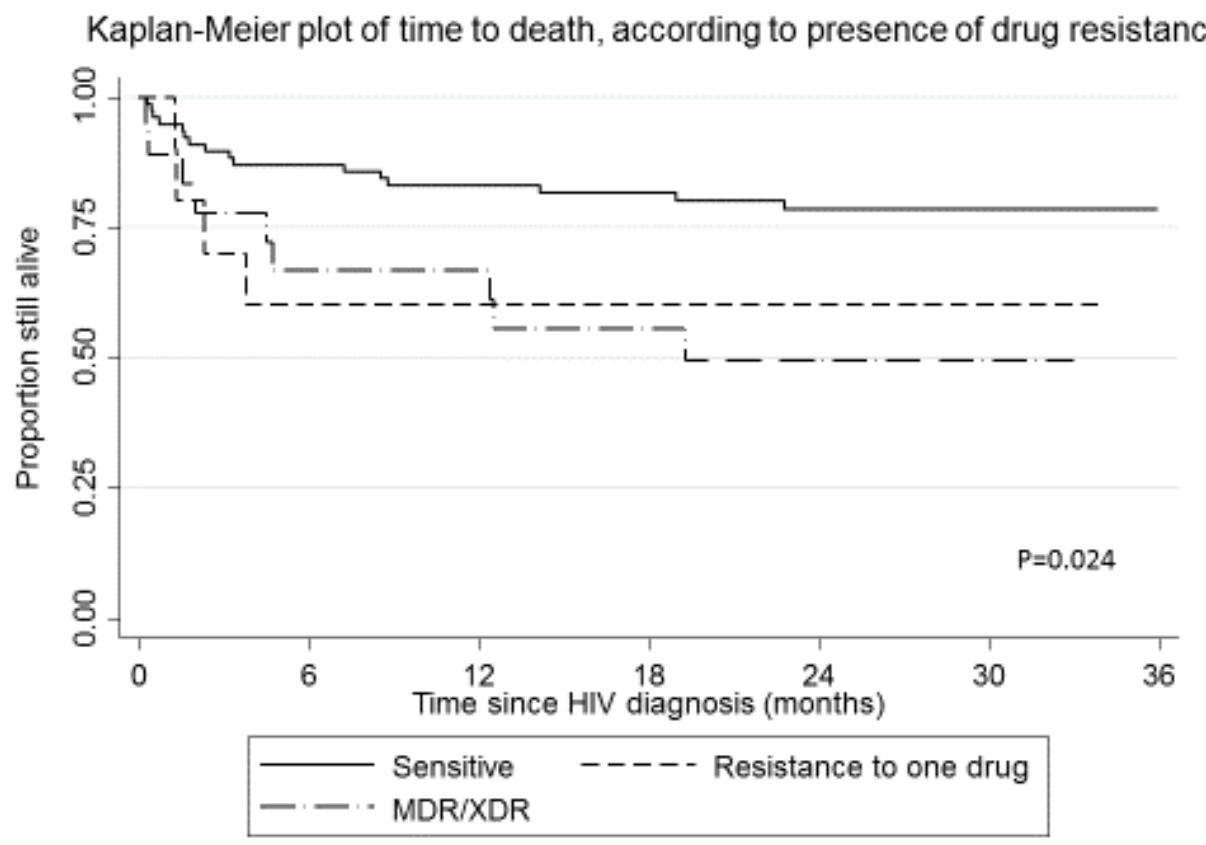

